\title{
Consumers' trust of salesperson and manufacturer: an empirical study
}

\author{
Mary Susan Kennedy ${ }^{\mathrm{a}, *}$, Linda K. Ferrell ${ }^{\mathrm{b}, 1}$, Debbie Thorne LeClair ${ }^{\mathrm{c}, 2}$ \\ ${ }^{a}$ Business Department, Columbia State College, P.O. Box 1315, Columbia, TN 38402-1315, USA \\ ${ }^{\mathrm{b}}$ Department of Marketing, University of Northern Colorado, Greeley, CO 80639, USA \\ ${ }^{c}$ College of Business and Industry, Mississippi State University, Mississippi State, MS 39762, USA
}

Received 1 December 1998; accepted 1 December 1998

\begin{abstract}
A positive model of consumers' trust of salesperson and manufacturer is developed which provides suggestions for improving relationships and increasing buyer-seller trust. The findings indicate that buyer-seller trust results from salesperson competence, lowpressure selling tactics, service quality, manufacturer ethical concern, and a general tendency to trust others. Product familiarity acts to decrease the overall trust of the salesperson. Manufacturer trust is fostered by satisfaction with the ownership experience, through the antecedents of satisfaction (salesperson competence, low-pressure selling tactics, product quality, and manufacturer ethical concern), and a general tendency to trust others. Global managerial implications and directions for future research are provided. (C) 2000 Elsevier Science Inc. All rights reserved.
\end{abstract}

Keywords: Consumers' trust; Salesperson; Manufacturer

Increasingly, businesses are focused on the development of long-term and mutually beneficial relationships with customers, other organizations, and employees. An essential ingredient in successfully achieving these long-term relationships is the establishment and maintenance of trust. This emphasis on trust has widespread applicability to a crosssection of organizations, including organizations selling to businesses, the final consumer, and non-profits and governmental agencies. From a global perspective, trust is one of the more difficult concepts to achieve on a cross-cultural basis. For example, both Fukuyama (1995) and Hosmer (1995) have noted the importance of societal-level trust in the development of mutually satisfying business relationships. Further, in a study by Yankelovich Partners, US consumers voiced a general lack of trust of business organizations (Berry, 1995).

From an intuitive perspective, trust between buyers, sellers, and other exchange participants such as manufacturers, facilitates long-term relationship development. The so-called soft skill of relationship management can have a tangible effect on business performance through customer

\footnotetext{
* Corresponding author. Tel.: +1-615-540-2674.

1 Tel.: +1-970-266-9676.

2 Tel.: +1-813-253-3333 ext. 3094; fax: +1-813-258-7408.
}

retention, employee loyalty and related outcomes. As Doney and Cannon (1997) have stated, high levels of trust "enable parties to focus on ... the relationship, ultimately enhancing competitiveness and reducing transaction costs" (p. 35). Thus, the practical benefits of trust in business are relevant for academic consideration.

Paralleling the interest among practitioners in developing and maintaining long-run relationships is the growing interest in organizational trust in many academic disciplines (e.g. Arndt, 1979; Anderson and Narus, 1986; Dwyer and Oh, 1988; Dwyer et al., 1987; Heide and John, 1988, 1990, 1992; Hallen et al., 1991; Moorman et al., 1993; Kurland, 1996). Despite the apparent importance of the trust concept in varying types of exchange relationships, this topic has not been researched extensively. A review of the literature reveals some gaps in our understanding of how trust specifically affects business relationships.

Only recently has trust been examined as it relates to buyer-seller interaction (Parasuraman et al., 1991; Morgan and Hunt, 1994; Berry, 1995). First, most of the emphasis regarding the role of trust is on relationships developed at the organizational level or in business-to-business exchanges, not between organizations and consumers (e.g. Swan et al., 1985; Hawes et al., 1989; Moorman et al., 1993; Doney and Cannon, 1997). Second, the majority of the previous studies pertaining to trust have focused 
predominately on just one antecedent area of trust development, the role of buyer-seller interaction (c.f. Swan et al., 1988; Crosby et al., 1990; Lagace et al., 1991). Although buyer-seller characteristics and behaviors are obviously one important factor in the development of buyer trust, there are likely other salient variables, such as product and company factors, which may influence trust formation. Third, some constructs, which are potentially significant to the development of a trusting relationship, such as ethics and service quality, have received little or no attention in empirical research thus far. Fourth, the relationship between trust and satisfaction, another highly sought buyer outcome, has scarcely been researched. Previous research has shown these constructs are positively correlated (e.g. Crosby et al., 1990; Lagace et al., 1991), but the causal ordering of the two has not been addressed. Fifth, empirical studies have looked at the relationship between trust and perceived ethics of the organization (e.g. Lagace et al., 1991), but this is still an emerging topic of interest. Sixth, although it is frequently suggested that trust in an economic exchange relationship is based on direct experiences and develops in stages over time (Swan et al., 1985; Dwyer and Lagace, 1986; Dwyer et al., 1987), there has been no empirical investigation, thus far, which focuses exclusively on the most critical stage in trust development, the exploration stage (Dwyer et al., 1987). Exploration is important because it is in this phase that the buyer searches for information, makes the initial purchase, and starts the process of developing trust. It is after the product is purchased, used, and evaluated that trust either continues to develop or deteriorates.

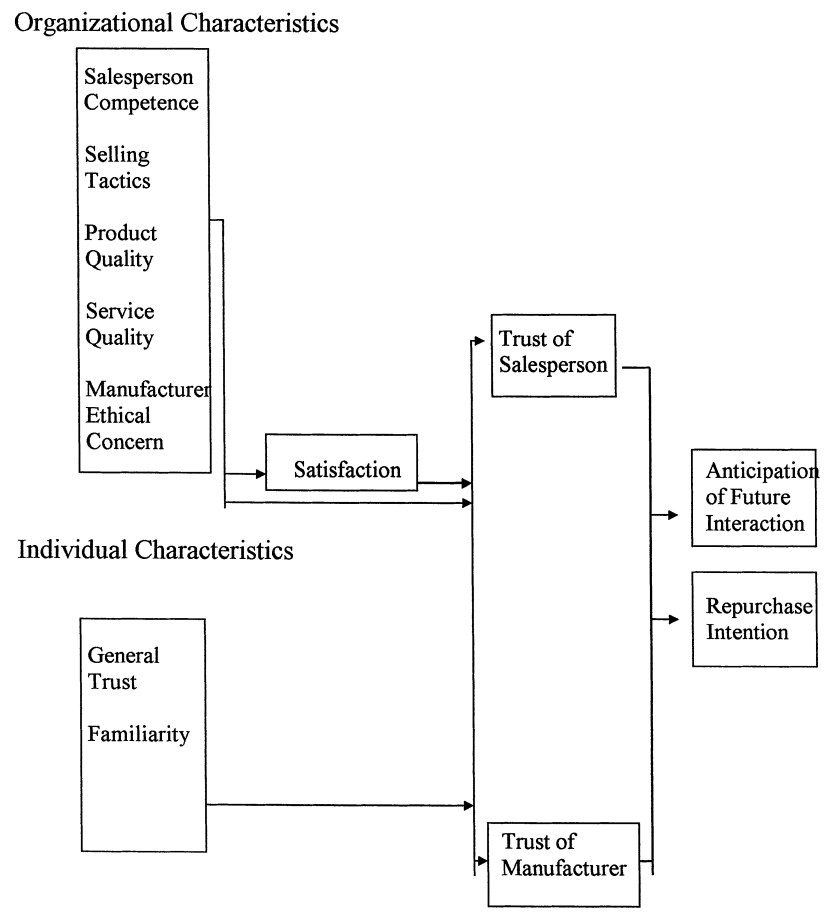

Fig. 1. Conceptual model.
The study described in this paper addresses several research gaps delineated above by developing and testing a conceptual model of consumer trust of salesperson and manufacturer. The model is based on conceptual and empirical studies in several areas of business and social science, including industrial sales, marketing, channels of distribution, and group and interpersonal relationships. The purpose of this study is to assess the role of trust in business relationships, with a focus on the characteristics of the salesperson, manufacturer, and the product ownership experience that contributes to this relationship. First, we provide a brief background on trust. Then we develop a conceptual model (shown in Fig. 1) and discuss the hypothesized relationships between the constructs. We examine these relationships by studying consumers who have recently purchased an expensive, high involvement, durable product that is subject to daily use and evaluation. The sample consisted of purchasers of 'domestic' and 'foreign' automobiles to gain a more global perspective on the construct of trust. Finally, we discuss a number of potential implications for both academic research and business practice.

\section{Conceptual foundation and hypotheses}

The concept of trust has been examined both conceptually and empirically, particularly in the context of interpersonal and small group research (c.f. Zand, 1972; Worchel, 1979). As with other terms which have widespread use in everyday language (such as "power"), there does not appear to be a single, commonly accepted definition of trust (Hosmer, 1995), although most definitions fit into one of three categories. Drawing from Worchel (1979), the first category focuses on trust as a personality trait or a response pattern attributable to early socialization and therefore, a function of an individual's specific environment. Rotter (1967, p. 653), in an earlier conceptualization, described trust as a "generalized expectancy that the word, promise, oral or written statement of another can be relied on". In the second category, trust is viewed as a risking behavior evaluated on a situation-by-situation basis by the individual. Based on Deutsch (1958), the trusting person is considered vulnerable, at risk of potential harm or loss if the trusted person takes advantage of that vulnerability (Dwyer and Lagace, 1986). Matthews and Shimoff (1979, pp. 538-539) describe a trusting response as "one by which persons commit themselves to possible loss depending on the subsequent behavior of other persons". The third category describes trust as a predisposition an individual holds toward another person or group, a perception that the other is helpful, cooperative, and honest (Pruitt, 1965). This conceptualization emphasizes dyadic or intergroup relations.

The marketing literature also contains several definitions of trust, including those by Crosby et al. (1990), Morgan and Hunt (1994), and Doney and Cannon (1997). In addi- 
tion, perhaps the most exhaustive attempt to review and conceptualize trust was performed by Hosmer (1995). By reviewing all the organizational theory conceptualizations of trust and those in related disciplines, Hosmer proposed the following definition: "Trust is the reliance by one person, group or firm upon a voluntarily accepted duty on the part of another person, group or firm to recognize and protect the rights and interests of all others engaged in a joint endeavor or economic exchange" (p. 393). Although other definitional approaches have merit and applicability to business exchange, the research presented here utilizes the perspective offered by Hosmer (1995).

\subsection{Review of trust literature}

Dwyer and Lagace (1986) developed one of the first frameworks of business trust relationships. In this framework, each party's propensity to trust is shown to stem primarily from direct experience with the exchange partner and is therefore situational. These experiences are posited to influence the perception of the buyer (seller) as being fair, honest, and cooperative. These perceptions, along with the individual's personality, affect the buyer's (seller's) propensity to trust the seller (buyer). When the trusting propensities of the buyer and seller are jointly considered, several possible relational forms occur - mutual high trust, mutual low trust, and mixed levels of trust between buyer and seller. Further, buyers and sellers will have to develop these levels of trust.

Another model of trust in business relationships was developed and tested by Holden (1990). This analysis indicated that both salesperson variables (e.g. salesperson personality, selling tactics, customer orientation, expertise) and company variables (e.g. product quality, customer service, customer orientation, expertise) are positively related to trust in the salesperson and trust in the company. Results indicated that both trust in the seller and in the company are positively related to loyal purchasing and cooperative negotiations. Fundamental to relationship building in marketing is the element of trust, which bonds the buyer and seller (Morgan and Hunt, 1994). Some studies have found interdependence between the buyer and seller to be a stronger predictor of relationship strength, whereas more recent research has found trust to be a more significant predictor (Ganesan, 1994; Berry, 1995).

Dwyer et al. (1987) have published probably the most comprehensive framework of the development of trust in business relationships. Their framework, which draws from Scanzoni (1979), suggests that these relationships evolve through the following five general phases: (1) awareness, (2) exploration, (3) expansion, (4) commitment, and (5) dissolution. Each phase involves different types and levels of interaction, each having implications for the establishment of expectations, direct experiences, and interdependence. For example, in the exploration phase, the subprocesses of attraction, communication and bargaining, development and exercise of power, norm development, and expectations development set the tone for a future of trust or distrust. Exploration continues after the initial purchase for products and services that provide a promise of long-term performance.

Along with the development of models of trust in business, empirical research in this area has focused on delineating attributes and behaviors which foster trust on the part of the buyer. Swan et al. (1985) studied how industrial salespeople gain the trust of customers, finding that customer trust is based on the salesperson being perceived as dependable, honest, competent, likable, and having a customer orientation. In their study of trust development of buyers and sellers, Hawes et al. (1989) discovered that the two groups' perceptions of "trust earning" variables differed. Both buyers and sellers agreed that a salesperson being "likable," "competent," and "dependable" allows the salesperson to earn the trust of the buyer. However, in relation to the buyers, the salespeople consistently overestimated the value of these variables.

Finally, Crosby et al. (1990) regard trust, along with satisfaction, as a component of relationship quality. In their study of selling complex services, results indicated that relational selling behaviors (high contact intensity, mutual disclosure, and cooperative intentions) and salesperson expertise positively influence relationship quality. In addition, relationship quality was found to significantly influence the customer's anticipation of future interaction with the salesperson, but not sales effectiveness.

\subsection{Hypothesized relationships}

The conceptual model presented in Fig. 1 focuses on the development of trust near the end of the exploration phase of the business relationship development process (Dwyer et al., 1987). It is proposed that the buyer develop an attitude of trust/distrust of the seller (both the individual salesperson and the manufacturer) based on his/her perceptions of the initial experience with the salesperson and product. For most purchasers of high involvement products that are used frequently and evaluated over time, exploration continues after the initial purchase. The product performance and trust cannot be determined at the point of purchase.

Salesperson competence and selling tactics are proposed to help create a perception of buyer trust/distrust. The level of perceived product and service quality is also viewed as influential. Further, the ethics of the manufacturer is viewed as relevant in influencing perceptions of trust. Of the individual characteristics, the level of familiarity with the product influences trust as does the overall trust orientation of the individual. A trusting relationship can extend beyond that of buyer-seller to one of organizational trust extending to the retailer or manufacturer (Sheth and Parvatiyar, 1996).

The organizational characteristics are thought to have a direct influence on the trust variables (salesperson and 
manufacturer) and an indirect effect through their positive influence on customer satisfaction. Satisfaction, which represents an overall assessment of the buying experience to date, is thought to directly influence trust of both the salesperson and the manufacturer. Both trust of the salesperson and trust of the manufacturer are expected to positively impact behavioral intentions of repurchasing the product and anticipating future interaction with the salesperson.

The research hypotheses are grouped into the following five major categories: satisfaction, trust of the salesperson, trust of the manufacturer, anticipation of future interaction with the salesperson, and repurchase intention. Based on the conceptual model, the following rationale assisted in hypothesis development.

\subsubsection{Satisfaction}

Crosby et al. (1990) found that expertise positively influences relationship quality. Product/market knowledge on the part of the salesperson is often considered an important criteria in determining customer satisfaction with salespeople (Anonymous, 1984). Therefore, it is proposed that there is a positive relationship between satisfaction and salesperson competence.

Weitz (1981) suggested that the use of high pressure selling tactics may sacrifice a customers' long-term satisfaction. Supporting this, Scheer and Stern (1992) found that more dominating influence types result in less satisfaction. Therefore, the use of low-pressure selling tactics is thought to increase satisfaction.

Intuitively, a product perceived to be of higher quality would instill a higher level of satisfaction than one of lower quality. Service quality has also been linked to customer satisfaction. Parasuraman et al. (1985) proposed that higher levels of perceived service quality would result in greater customer satisfaction, and Cronin and Taylor (1992) provided empirical support. In marketing relationships, service experiences are key opportunities to enhance buyer-seller relations and improve trust (Bitner 1995).

(1) Customer satisfaction with the product ownership experience is

(a) positively associated with salesperson competence.

(b) positively associated with low-pressure selling tactics.

(c) positively associated with product quality.

(d) positively associated with service quality.

(e) positively associated with manufacturer ethical concern.

\subsubsection{Trust of the salesperson and manufacturer}

Trust has been related to salesperson competence. Holden (1990) demonstrated that salesperson product expertise is positively related to both trust of the salesperson and trust of the company. Just as Moorman et al. (1993) found that expertise of a market researcher positively influences trust by the user, salesperson competence is thought to positively influence the consumer's trust of the salesperson.

In the development of both trust of the company and of the salesperson, Holden (1990) found that high-pressure selling tactics seem to inhibit trust development. In an experimental setting, Scheer and Stern (1992) discovered that more dominating influence tactics result in lower levels of trust. Therefore, low-pressure selling tactics are thought to create greater trust of the salesperson. Following Holden (1990), it is suggested here that the salesperson factors that increase trust of the salesperson will also increase the trust of the retailer and manufacturer. It is believed there will be a halo effect. A good experience with the salesperson reflects positively on both the retailer and manufacturer. Training, hiring, and managing the salesperson is a result of corporate and retailer initiatives.

Product quality is related to both trust of the salesperson and trust of the company. Since trust is thought to be primarily based on experience, an assessment of the product's quality occurs over time. It is proposed that individuals who perceive higher levels of product quality will also show higher levels of trust of both the salesperson and manufacturer. Thus, consumers who believe the product is of high quality will be more likely to trust the claims and general behavior of both salespeople and the product manufacturer. This rationale should also hold for service quality, such that as customers experience excellent service, they will also develop trust for the actions of the seller/ service provider. As with perceived product quality, it is proposed that perceived service quality would impact perceptions of trust.

Moorman et al. (1993) found that two characteristics of market researchers' organizations, the culture and the level of power, had an impact on trust formation. The ethical concern of an organization's culture has been found to influence the attitudes and behaviors of its members (e.g. Ferrell and Weaver, 1978; Kelley et al., 1989; Herndon, 1991; Kelley and Dorsch, 1991). It is proposed in this study that a company's perceived ethical concern can also influence its customers' attitudes. In this study, manufacturer ethical concern is thought to be positively related to the buyer's trust of the manufacturer. Just as salesperson factors are likely to influence trust of the manufacturer, in general, manufacturer characteristics will likely impact perceptions of trust of the salesperson.

The buyer's overall satisfaction with the buying experience is proposed to have a positive impact on his/her trust of both the salesperson and the manufacturer. Previous research has shown that constructs of trust and satisfaction are positively correlated (e.g. Crosby et al., 1990), but the causal ordering of the two has not been assessed. Therefore, it is proposed that customer satisfaction is an antecedent of both trust of the salesperson and trust of the manufacturer.

People tend to exist somewhere on a spectrum between trusting and non-trusting attitudes (Worchel, 1979). An 
individual's generalized tendency to trust is considered to be an important variable in the development of trusting relationships (Swan and Nolan, 1985). Thus, we would expect those buyers who have a general trusting attitude to find it easier to trust the salesperson and manufacturer.

Another factor that may influence levels of trust is the individual's familiarity with the product prior to the purchase experience. Someone with a high level of product knowledge would probably be more likely to trust both the salesperson and the manufacturer than would the individual with little prior knowledge of the product. The following hypotheses are proposed relative to the antecedents of trust of the salesperson and trust of the manufacturer.

(2) The customer's trust of the salesperson is

(a) positively associated with salesperson competence.

(b) positively associated with low-pressure selling tactics.

(c) positively associated with product quality.

(d) positively associated with service quality.

(e) positively associated with manufacturer ethical concern.

(f) positively associated with satisfaction.

(g) positively associated with general tendency to trust.

(h) positively associated with familiarity with the product.

(3) The customer's trust of the manufacturer is

(a) positively associated with salesperson competence.

(b) positively associated with low-pressure selling tactics.

(c) positively associated with product quality.

(d) positively associated with service quality.

(e) positively associated with manufacturer ethical concern.

(f) positively associated with satisfaction.

(g) positively associated with general tendency to trust.

(h) positively associated with familiarity with the product.

\subsubsection{Anticipation of future interaction with the salesperson}

The anticipation of future interaction is considered a goal of many business and relationship encounters (Kellerman, 1987). High expectation of future interaction would be fostered by a positive perception of the current relationship, while low expectations of future interaction would be the result of an unpleasant relationship. For the purposes of this study, anticipation of future interaction focuses on the buyer's desire to interact with the salesperson that served him/her in the initial purchase of the product, if the need should arise again.

Trust is thought to be one key component of a lasting exchange relationship. A buyer who trusts the seller is more likely to want to continue his/her interaction than a buyer is with a low level of trust. Crosby et al. (1990) found that relationship quality (trust and satisfaction) is positively related to the anticipation of future interaction. Similarly, the results of Moorman et al. (1993) indicated that trust in the researcher positively influences user commitment to the research relationship. The buyer's trust of the salesperson and the manufacturer is proposed to positively influence the buyer's anticipation of future interaction with the salesperson. The following hypotheses are proposed concerning anticipation of future interaction with the salesperson.

(4) Anticipation of future interaction with the salesperson is

(a) positively associated with trust of the salesperson.

(b) positively associated with trust of the manufacturer.

\subsubsection{Repurchase intention}

Repurchase intention is defined here as the intention to repurchase a particular brand of product again. A buyer who has higher levels of trust of the salesperson and the manufacturer with which he/she has had experience is more likely to repurchase that brand than is the customer with lower levels of trust. Holden (1990) found that one of the outcomes of both trust of the salesperson and trust of the company is purchasing loyalty. The buyer's trust of the salesperson and the company is proposed to positively influence the buyer's repurchase intentions. The following hypotheses are suggested regarding the impact of trust on repurchase intention.

(5) Repurchase intention is

(a) positively associated with trust of the salesperson.

(b) positively associated with trust of the manufacturer.

\section{Methodology}

\subsection{Sample}

The sample used to test the research hypotheses included selected car buyers who had owned new automobiles for approximately 6 months. The sample consisted of first time buyers of Saturn and Toyota vehicles. Auto purchases are high involvement decisions where salesperson and manufacturer trust plays a key role in the purchase decision. An R.L. Polk list of 2000 new purchasers of Toyota Corolla Sedans, Wagons, and Celicas was used. The buyers were randomly selected from 33 states and the District of Columbia. Saturn made a comparable list of their car buyers available from the states matching the Toyota car buyers' list, with the agreement that all respondents would be grouped together in the analysis.

At the time of the study, Saturn ranked number one in customer satisfaction with dealers and Toyota ranked below the industry average in customer satisfaction with retailers (Florida Today, 1998). Saturn maintains a "buyer sensitive" strategy with its use of non-negotiable pricing and a web site providing comprehensive purchase information. Purchasers of Saturn automobiles are not exposed to high pressure selling tactics. Both Saturn and Toyota 
automobiles are available in the US and abroad. Saturn represents a US manufacturer and Toyota represents a Japanese manufacturer.

The questionnaire was pre-tested for readability and clarity with undergraduate business students. Four thousand questionnaires were mailed first class to Toyota and Saturn buyers. To encourage a high return, respondents were given the opportunity to request a summary of the research findings. Table 1 provides sample characteristics for the 786 questionnaires returned. Eighty-two questionnaires were returned as non-deliverable, resulting in an effective response rate of $20 \%$.

Table 1

Characteristics of respondents

\begin{tabular}{|c|c|c|}
\hline Category & Frequency & Percent \\
\hline \multicolumn{3}{|l|}{ Gender } \\
\hline Male & 256 & 38.4 \\
\hline Female & 411 & 61.6 \\
\hline \multicolumn{3}{|l|}{ Age } \\
\hline Under 25 & 95 & 12.2 \\
\hline $25-30$ & 147 & 18.9 \\
\hline $31-35$ & 85 & 10.9 \\
\hline $36-40$ & 98 & 12.6 \\
\hline $41-45$ & 88 & 11.3 \\
\hline $46-50$ & 69 & 8.9 \\
\hline $51-55$ & 70 & 9.0 \\
\hline $56-60$ & 32 & 4.1 \\
\hline $61-65$ & 32 & 4.1 \\
\hline Over 65 & 63 & 8.1 \\
\hline \multicolumn{3}{|l|}{ Education } \\
\hline Some high school & 11 & 1.4 \\
\hline High school graduate & 92 & 11.8 \\
\hline Trade/technical school & 34 & 4.4 \\
\hline Some college & 185 & 23.7 \\
\hline College graduate & 236 & 30.3 \\
\hline Some post graduate work & 83 & 10.7 \\
\hline Post graduate degree & 138 & 17.7 \\
\hline \multicolumn{3}{|l|}{ Ethnic origin } \\
\hline African-American & 28 & 3.7 \\
\hline American Indian & 5 & 0.6 \\
\hline Asian & 18 & 2.3 \\
\hline Caucasian & 671 & 85.4 \\
\hline Hispanic & 27 & 3.5 \\
\hline Other & 17 & 2.2 \\
\hline \multicolumn{3}{|l|}{ Income } \\
\hline Under $\$ 30,000$ & 139 & 19.2 \\
\hline$\$ 30,000-39,999$ & 119 & 16.4 \\
\hline$\$ 40,000-49,999$ & 128 & 17.7 \\
\hline$\$ 50,000-59,999$ & 87 & 12.0 \\
\hline$\$ 60,000-69,999$ & 78 & 10.8 \\
\hline$\$ 70,000-79,999$ & 69 & 9.5 \\
\hline$\$ 80,000-89,999$ & 30 & 4.1 \\
\hline$\$ 90,000-99,999$ & 16 & 2.2 \\
\hline$\$ 100,000-124,999$ & 26 & 3.6 \\
\hline$\$ 125,000-149,999$ & 16 & 2.2 \\
\hline$\$ 150,000$ and above & 16 & 2.2 \\
\hline
\end{tabular}

\subsection{Measurement scales}

\subsubsection{Salesperson competence}

This construct was measured using the "competent" portion of the scale developed by Swan et al. (1988). The four-item scale has reported reliability of 0.86 . Whereas Swan et al. (1988) viewed this construct as a dimension of salesperson trust, it is argued in this research that salesperson competence is an antecedent of trust of the salesperson. Factor analysis indicated that competence was essentially distinct from other salesperson dimensions of responsibility, dependability, and likability, providing some evidence of the discriminant validity of this measure (Swan et al., 1988).

\subsubsection{Selling tactics}

A two-item measure used by Holden (1990) is the basis of a scale to assess the level of high/low-pressure selling tactics used by the salesperson. Since the original Holden (1990) scale had a reported coefficient alpha of only 0.60, two items were added to the scale to attempt to improve its reliability.

\subsubsection{Product quality}

The product's perceived quality was measured using a six-item, seven-point semantic differential summated ratings' scale developed by Petroshius and Monroe (1987) to measure the perceived quality of typewriters and calculators. The scale has reported coefficient alphas of 0.88 and 0.84 in previous research. Also, a factor analysis indicated that the items loaded together and not on other related factors, providing some evidence of convergent and discriminant validity (Petroshius and Monroe, 1987).

\subsubsection{Service quality}

A performance-based measure (SERVPERF) analyzed by Cronin and Taylor (1992) was used as the basis of a scale to assess perceived service quality. The SERVPERF scale was shown to be more efficient than the traditional SERVQUAL scale proposed by Parasuraman et al. (1985). The scale has reported coefficient alpha of 0.88 to 0.96 . SERVPERF measures the respondents' feelings about 22 attributes related to a company's service. Cronin and Taylor's (1992) study found this scale to be basically uni-dimensional and to have acceptable reliabilities (given above) in testing with four samples. In addition, their analysis indicated some degree of convergent and discriminant validity for the SERVPERF scale. SERVPERF correlated highly with other measures of service quality and also correlated more highly with other measures of service quality than it did with other research variables (satisfaction and purchase intentions). Ten items relevant to the servicing of automobiles were chosen from the SERVPERF scale to measure perceived service quality in this study. 


\subsubsection{Manufacturer ethical concern}

One dimension of a scale developed by Victor and Cullen $(1987,1988)$ to measure ethical climate of an organization was used as the basis for the measure of manufacturer ethical concern. The original scale has been used to assess perceptions of organizational members. For this research, the scale was revised to reflect customer perceptions of organizational behavior rather than employee perceptions of expected organizational behavior.

Although the original measure assesses five distinct dimensions of ethical climate, only one dimension, caring (i.e. benevolence, acts of kindness), was used for this study. Consultation with the director of marketing research for Saturn indicated that the caring dimension was the most relevant in this situation and the one customers might be able to evaluate. The scale consists of seven statements. The coefficient alpha for the caring dimension is reported as 0.80. (Victor and Cullen, 1988).

\subsubsection{General trust}

To measure the buyer's generalized tendency to trust, a five-item scale developed by Holden (1990) was used. In Holden's (1990) research, the scale has a reported coefficient alpha of 0.71 . Factor analysis indicated that the "General Trust" scale was distinct from two other measures of trust, "Sales Trust" and "Company Trust," providing some evidence of discriminant validity (Holden, 1990).

\subsubsection{Familiarity with the product}

The buyer's familiarity with the product prior to its purchase was measured using a three-item, seven-point semantic differential scale developed by Oliver and Bearden (1985). The scale has a reported coefficient alpha of 0.85 . In its development, a confirmatory factor analysis was performed once; weak items were deleted, and the analysis was run again, resulting in higher overall factor loadings (Oliver and Bearden, 1985). The scale was revised slightly to reflect the car purchase situation.

\subsubsection{Satisfaction}

Customer satisfaction was measured using a six-item, semantic differential scale used by Oliver and Swan $(1989 a, b)$ with reported coefficient alpha of 0.91 and higher. For their studies, Oliver and Swan (1989a,b) adapted a seven-item version of the scale, originally developed by Westbrook and Oliver (1981) to measure satisfaction with cars and with calculators. Although no specific scale validation is reported by Oliver and Swan (1989a,b), the scale in its original form showed strong evidence of construct validity by converging with like constructs and discriminating between unlike constructs (Westbrook and Oliver, 1981). The measure was used to assess the buyer's satisfaction with his/her ownership experience to date.

\subsubsection{Trust of salesperson}

Holden's (1990) "Sales Trust" scale was used to assess trust of the salesperson. Holden's (1990) original scale, developed to assess trust in an industrial business relationship, has eight items and a reported coefficient alpha of 0.92. Factor analysis provided some evidence of the discriminant validity of this measure, as items from each trust scale loaded into three separate and distinct factors, "Sales Trust," "Company Trust," and "General Trust" (Holden, 1990).

\subsubsection{Trust of a manufacturer}

A similar scale was devised to measure "Company Trust" (Holden, 1990). This scale has a reported coefficient alpha of 0.73 . This four-item scale was used to measure trust of the manufacturer in this study. The scale's validity was assessed as described in the previous subsection.

\subsubsection{Anticipation of future interaction}

Anticipation of future interaction with the salesperson was measured using a four-item, seven-point semantic differential scale developed by Oliver and Swan (1989a). This scale is designed to measure intentions to reuse a salesperson. This scale has a reported coefficient alpha of 0.96 .

\subsubsection{Repurchase intention}

Intention to repurchase was measured by four-item, seven-point semantic differential scale that assessed the respondents' willingness to purchase a car from the same manufacturer again. The scale was adapted from the 'Anticipation of Future Interaction' scale developed by Oliver and Swan (1989a).

\section{Analysis}

Table 2 provides results from the factor and reliability analysis for the measurement scales. The specific items for each measure are provided in the Appendix. Scale assessments consisted of exploratory factor analysis (Kim and Mueller, 1978) and reliability assessment via the use of coefficient alpha (Cronbach, 1951). Principal components factor analysis was used with orthogonal rotation to ascertain the minimum number of factors accounting for variation within each measure. A minimum value of 0.40 was used to indicate the loading of a scale item on any factor (Pedhazur, 1982).

Factor analysis indicated that each measure, with the exception of product quality, consisted of one factor, as anticipated. Product quality produced a two-factor solution. However, examination of the item loadings revealed that the second factor may have been a "methods" factor, since it was comprised of statements with response categories that are reversed, negative to positive, from the response categories for all other items. As a result, these items were 
Table 2

Path analysis results

\begin{tabular}{|c|c|c|c|c|}
\hline \multirow{2}{*}{$\begin{array}{l}\text { Path between variables } \\
\text { Salesperson competence-satisfaction }\end{array}$} & \multicolumn{2}{|c|}{$\begin{array}{l}\text { Theoretical models } \\
\text { (Standard coefficient } / t \text {-value) }\end{array}$} & \multicolumn{2}{|c|}{$\begin{array}{l}\text { Trimmed model } \\
\text { (Standard coefficient } / t \text {-value) }\end{array}$} \\
\hline & $0.128^{*}$ & 3.115 & $0.130^{*}$ & 3.216 \\
\hline Selling tactics & $0.090^{*}$ & 2.407 & $0.091 *$ & 2.444 \\
\hline Product quality & $0.440^{*}$ & 12.077 & $0.442 *$ & 12.483 \\
\hline Service quality & 0.016 & 0.325 & & \\
\hline Manufacturer ethical concern & $0.199 *$ & 4.109 & $0.208^{*}$ & 5.277 \\
\hline Salesperson competence-trust of salesperson & $0.288^{*}$ & 8.344 & $0.293 *$ & 8.5277 \\
\hline Selling tactics & $0.258^{*}$ & 8.176 & $0.262 *$ & 8.337 \\
\hline Product quality & -0.023 & -0.675 & & \\
\hline Service quality & $0.167 *$ & 4.025 & $0.166^{*}$ & 4.108 \\
\hline Manufacturer ethical concern & $0.233^{*}$ & 5.659 & $0.241^{*}$ & 5.979 \\
\hline General trust & $0.117 *$ & 4.100 & $0.117 *$ & 4.097 \\
\hline Familiarity & $-0.068^{*}$ & -2.404 & $-0.066^{*}$ & -2.366 \\
\hline Satisfaction & 0.043 & 1.205 & & \\
\hline Salesperson competence-trust of manufacturer & -0.008 & -0.301 & & \\
\hline Selling tactics & 0.016 & 0.661 & & \\
\hline Product quality & 0.027 & 0.979 & & \\
\hline Service quality & 0.061 & 1.873 & & \\
\hline Manufacturer ethical concern & $0.745^{*}$ & 22.881 & $0.788^{*}$ & 31.414 \\
\hline General trust & $0.068^{*}$ & 3.069 & $0.070^{*}$ & 3.106 \\
\hline Familiarity & 0.004 & 0.164 & & \\
\hline Satisfaction & $0.087^{*}$ & 3.060 & $0.109^{*}$ & 4.452 \\
\hline Trust of salesperson-anticipation of future interaction & 0.724 & 19.439 & $0.724 *$ & 19.617 \\
\hline Trust of manufacturer & $-0.087^{*}$ & -0.2341 & $-0.087^{*}$ & -2.363 \\
\hline Trust of salesperson-repurchase intention & $0.201 *$ & 4.500 & $0.202 *$ & 4.541 \\
\hline Trust of manufacturer & $0.337 *$ & 7.534 & $0.338^{*}$ & 7.604 \\
\hline Coefficient of determination of structural equations & 0.883 & & 0.884 & \\
\hline Chi-square & 276.24 & & 284.07 & \\
\hline$P$-value & 0.000 & & 0.000 & \\
\hline Degrees of freedom & 53 & & 61 & \\
\hline Goodness of fit Index & 0.924 & & 0.923 & \\
\hline Adjusted goodness of Fit index & 0.702 & & 0.786 & \\
\hline
\end{tabular}

* $t$-values $>2.0, p<0.05(n=547)$.

forced to a single-factor solution. Finally, the coefficient alphas for each scale exceeded the 0.70 standard determined by Nunnally (1978).

The entire model was tested through the use of path analysis via LISREL (Bollen, 1989). Path analysis is a technique for examining both the direct and the indirect effects of independent variables on outcome variables (Pedhazur, 1982). The model to be tested was designed within a theoretical context, as the causal ordering of the variables was established before the procedure was conducted. Testing the full path model basically involved testing the fit between the data and the explanatory scheme that is hypothesized. In order to achieve a more parsimonious explanation of the relationships under study, model trimming was used. Model trimming is appropriate in exploratory research when path coefficients fail to reach statistical significance, as long as it is not used as a substitute for a priori hypothesis testing (Duncan, 1975; Pedhazur, 1982).

\subsection{Path analysis results}

The next step taken was to examine the hypotheses and the overall fit of the theoretical model using path analysis.
The path coefficients of both the theoretical and trimmed model are shown in Table 2. In addition, the theoretical model was trimmed, eliminating the non-significant paths, and tested for overall fit. The trimmed model is shown in Fig. 2.

The results indicate that both models moderately fit the data. Both models had coefficients of determination of approximately 0.88 , indicating that $88 \%$ of the variance in the dependent variables was jointly explained by the model variables. The chi-square statistic was 276.24 for the theoretical model and 284.07 for the trimmed model, with $p$ values of less than 0.01 . This test shows that there is a significant difference between the proposed models and the relationships among the data. However, it has been noted that the chi-square test of model fit is sensitive to sample size, rejecting virtually any model if it is large enough (Bagozzi, 1981).

The theoretical model had a goodness of fit (GFI) index of 0.924, with an adjusted goodness of fit (AGFI) index of 0.702. The fit indexes for the trimmed model, which were a GFI of 0.923 and an AGFI of 0.786, were roughly comparable. Ideally, both indexes should be above 0.9 to indicate a good fit of the model (Bagozzi and Yi, 1988). 


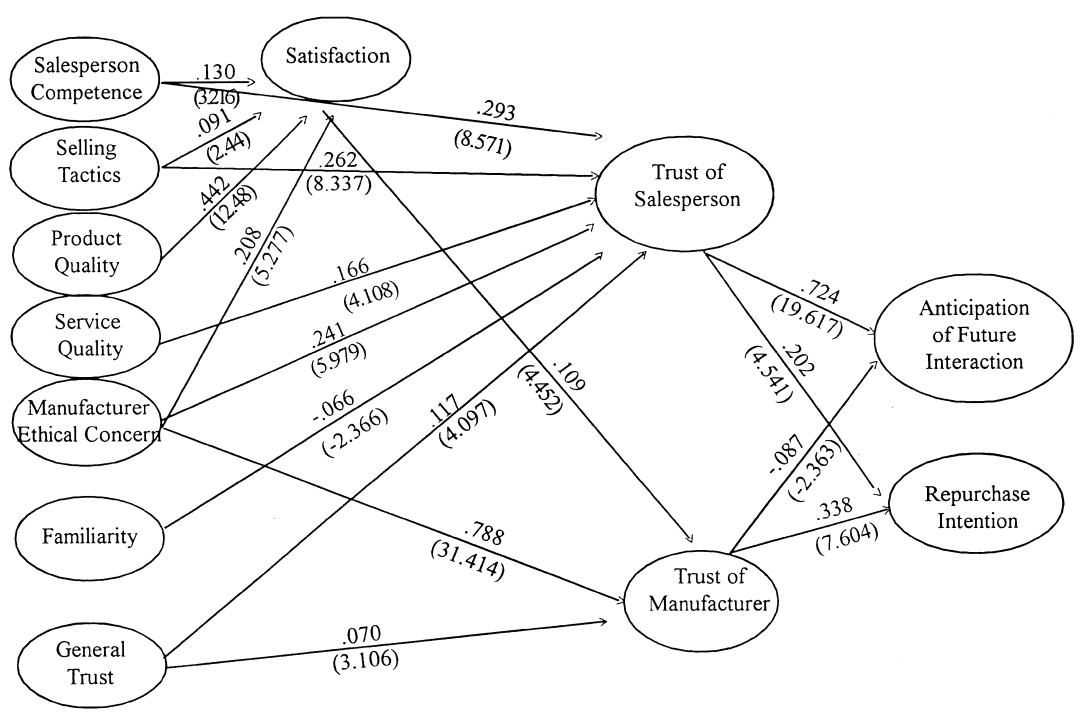

Fig. 2. Trimmed model of consumer trust in the automobile industry (all path coefficients listed have $t$-values $>2.0, p<0.5$ ).

The primary influences on satisfaction were found to be, in order of importance: product quality, the ethical concern of the manufacturer (caring), the competence of the salesperson, and the use of low-pressure selling tactics. The standardized regression coefficient of product quality was double that of any other antecedent variable. Results indicated that trust of the salesperson results from several different factors: salesperson competence, lowpressure selling tactics, service quality, manufacturer ethical concern (caring), and a general tendency to trust. Familiarity with the product prior to purchase seems to lower trust of the salesperson rather than increase it, as was expected.

Only three factors were found to directly influence trust of the manufacturer. Satisfaction with the purchase to date, manufacturer ethical concern (caring), and a general tendency to trust contribute directly to trust of the manufacturer. As salesperson competence, selling tactics, product quality and manufacturer ethical concern help create satisfaction, their influence on trust of the manufacturer is indirect.

Anticipation of future interaction with the salesperson appears to result primarily from trust of the salesperson. Trust of the manufacturer was found to negatively impact anticipation of future interaction of the salesperson. As hypothesized, both trust of the salesperson and trust of the manufacturer positively influence a customer's repurchase intention.

\section{Managerial implications}

As Hosmer (1996) wrote in his review of Business Ethics Quarterly's first 5 years, the business ethics discipline is in need of more articles that use empirical studies to validate theoretical relationships. This study is in line with Hosmer's recommendations for more empirical validation of descriptive theory. Although much of this article has relied on descriptive theory for its hypotheses, in the following section, we discuss some of the managerial implications arising from our results.

The findings of this research suggest several implications for practitioners, at both the retail and manufacturer level. At the retail level, salesperson behaviors and attributes influence customers' satisfaction with the product ownership experience and the customer's trust of the salesperson. This relationship alone has many implications for hiring and retaining good employees. Companies should design sales training programs that help salespeople become more competent and successful at using low-pressure selling tactics and the means that improve their competence and professionalism. A competent salesperson with complete and accurate product knowledge creates satisfaction. It is through this satisfaction that consumers develop trust of the manufacturer, as well as trust of the salesperson. Although many of us intuitively associate an employee with his or her parent company, these results are especially important for industries where "sellers" are not necessarily employed by the product's manufacturer. For example, customers may actually differentiate between the overall product experience and the service level they receive from the salesperson.

In this study, product quality was found to be the strongest indicator of ownership satisfaction, not service quality, ethical concern of the manufacturer or salesperson characteristics. Perhaps surprisingly, product quality did not help to create trust of the salesperson. This suggests that trust of the salesperson must be built on factors 
outside of the product itself and that buyers differentiate the roles of manufacturer (i.e. to create high quality products) and sales agent (i.e. to match products with customer needs). Again, this result may be common for business situations where the salesperson is not technically employed by the manufacturer.

Interestingly, service quality did not significantly contribute to satisfaction. In previous research, service quality has been found to be a predictor of satisfaction (Cronin and Taylor, 1992). There could be several possible explanations for this finding. At this point in the ownership experience, the car probably has been serviced only once. There are not as many problems with cars early in their life cycle and the servicing may be perceived as routine with high quality expected and not particularly noticed or appreciated. In this context, in the initial phase of car ownership, service quality may not be as important to consumers as other issues, such as overall product quality.

The perceived ethical concern of a manufacturer, specifically how much it seems to care about its customers, was found to play an important role in creating satisfaction with the ownership experience and trust of both the salesperson (at the retail level) and the manufacturer. Although many business ethicists have focused on linking organizational ethics with outcomes, such as profitability, this study provides preliminary evidence about proxies for business success, such as customer satisfaction and trust. Given its far-reaching impact, manufacturers, regardless of their country of origin, should work to create a caring attitude and convey this message to their customers.

In this study, persons who perceived themselves as knowledgeable about the product prior to its purchase had lower levels of trust of the salesperson. This finding suggests that salespeople should be trained to build trust with highly knowledgeable customers. This also suggests that some consumers who have taken the time to understand a product may have less need for a salesperson's assistance. With widespread Internet usage and information availability, consumers' product knowledge is likely to continue increasing. Consumers may also view any such help from a salesperson as more of an attempt to persuade or unduly influence them than to provide factual knowledge to assist in the decision making process. Salespeople need to understand how to appropriately manage the selling situation with customer groups that seek information before making purchases. Finally, it is not surprising that those customers who are generally predispositioned towards trusting attitudes were found to have trust in both the salesperson and manufacturer.

This research extends previous research in the area of trust in business, with a specific focus on relationships between consumers, retailers, and manufacturers. The findings indicate that there are multiple factors that create trust on the part of the consumer. Given the desire of many sellers to develop long-term relationships with customers, understanding how trust is developed is essential. Further, as both Zucker (1920) and Kurland (1996) have suggested, we need to recognize both the process by which trust is developed (interaction with retailer) and other important organizational signals and indicators of trust (i.e. professional accreditation and lack of disciplinary history). The empirical results presented in this paper offer a unique perspective for understanding the importance of business trust and specific relationships in the automobile industry.

Finally, a focus on business ethics provides an effective mechanism for enhancing trust in business relationships. Essentially, ethics facilitates the development of relationships that are formed on the basis of honesty and a belief on others' words and actions, something beyond legalities and contractual arrangements. Organizations concerned with building long-term relationships with consumers are concerned with more than just obeying the law (Berry, 1995), and trustworthiness acts as a measure of success in doing so. However, organizations have ways of encouraging or discouraging employees from building trust and relationships. These "work climates" have many dimensions, including an ethical dimension that relates to judgments about right or wrong behavior.

Unethical business climates have been suggested to lower the level of trust (Ferrell et al., 1989). This has been confirmed by Loe's (1996) empirical findings that higher perceptions of ethical climate are significantly related to higher levels of perceived intra-firm trust. Additional support indicates that when employees and the organization do not sacrifice ethical standards to achieve performance goals, organizational trust increases (Moorman et al., 1993). Finally, Lagace et al. (1991) found that ethical seller behavior has a strong positive influence on two aspects of relationship quality, trust, and satisfaction. Therefore, ethical behavior within the organization can have consequences for the seller, the seller's relationship with the organization, the buyer's level of satisfaction with the exchange, and ultimately, overall business performance.

\section{Limitations of the research}

The findings and implications derived from this research must be tempered by several limitations. First, the study took place within a single industry. While this approach limits the influence of extraneous factors based on industry differences, it may limit the generalizability of the findings to other consumer goods purchasing situations, particularly to the purchase of low involvement, non-durable products. The external validity of these findings would be greatest for other purchase situations involving durable products and a large expenditure, such as real estate and major appliances. 
Second, the sample used for this research was taken from two competing organizations within the automobile industry, both of which are known for producing high quality products although Saturn consistently receives higher dealer satisfaction ratings than Toyota. Consequently, there is less variation in responses than there would be if a more diverse group of manufacturers had been used to form the basis for sample selection. Third, because this research took place only 6 months after buyers purchased a new car, we have little empirical evidence of the latter stages of the trust development process. For example, it is likely that buyers will experience more problems with their cars and related services as the years pass. These experiences could have a profound influence on the (dis)trust in the relationship between consumer, dealer staff and salespeople, and the manufacturer.

Finally, another potential problem is that with this type of survey, only the very satisfied or very dissatisfied customer may respond, under-representing persons with moderate or mixed feelings. However, a return rate of $20 \%$ for this type of mass mailing with no financial incentive is deemed acceptable.

\section{Directions for future research}

Since no research, heretofore, has examined a more comprehensive model of the antecedents of trust at the consumer level, this research can serve as a guide for future study in this area. Previous research regarding trust has focused primarily on the exchange relationship at the organizational level, particularly on the role of the salesperson in creating trust on the part of the buyer. This study represents a step toward better understanding of the development of trust in the relationship between consumer and seller, focusing on multiple and relevant determinants.

Several avenues for future research can be suggested that would extend the findings of this research. First, similar research should be conducted with a greater variety of automobile producers and dealers and within other industries. Although multiple antecedents were considered, a major area for further research is the inclusion of other potentially relevant variables. Length of product ownership, product pricing, and manufacturer and/or dealer advertising and promotion are all potential moderators of consumer trust.

This study, conducted in the US, could be replicated in Japan where both brands are also sold. The cross-cultural perception of trust related to these two automobile brands could provide insights that could be useful in developing global brands. By exploring the concept of trust in different countries, a more global approach to marketing could be incorporated into strategic planning.

Another area for investigation would be to conduct a longitudinal study to determine how trust is developed over time. This research focused on the exploration stage of the business relationship, early in the life of the exchange relationship. This was a "snap shot" approach. It would be interesting to evaluate how and why trust levels change over time. For example, how long does the sales experience play a role in trust development? If the quality of the product declines with age, how is trust influenced? Are there societal-level factors, including laws, regulations, and public policies, that affect the development of trust over time?

This research effort examined the ethical concern of a manufacturer from the customer's point of view, which is rare in the business ethics literature. This differed from previous research that had studied organizational ethical concern from the employees' perspective. As manufacturer ethical concern played an important role in creating trust and satisfaction, it would be beneficial to study how this caring attitude is created on the part of the manufacturer. Another study could evaluate the types of signals that customers use to decide how ethically a company conducts its business.

A final area for future research relates to a system approach to understanding customer perceptions and attitudes. When buying at the retail level, a customer is potentially influenced by multiple departments within the retail organization as well as by impressions regarding the manufacturer of the particular product. The interaction among these factors in creating trust and satisfaction should be assessed further.

\section{Appendix A. Measurement scales and coefficient alpha}

Statements followed by (-) indicate reverse scoring.

Salesperson competence - seven-point scale: strongly disagree to strongly agree (0.97)

C1 In discussing the car, the salesperson knew what he/she was talking about.

C2 The salesperson was an excellent source of accurate product information.

C3 This salesperson knew as much as he/she should have about the product.

C4 This salesperson knows a lot about his/her product.

Selling tactics - seven-point scale: strongly disagree to strongly agree (0.83)

T1 He/she used a lot of high pressure selling tactics. (-)

T2 He/she tended to be a low-pressure salesperson.

T3 This salesperson was pushy. (-)

T4 This salesperson had an aggressive approach. (-)

Product quality - seven-point scale (0.71)

PQ1 The likelihood the car will be reliable is (very high to very low). (-)

PQ2 The workmanship of the car appears to be (very high to very low). (-)

PQ3 This car appears to be of (very good quality to very poor quality). (-) 
PQ4 I would consider this car to be very functional (strongly disagree to strongly agree).

PQ5 The likelihood that this car is dependable is (very high to very low). (-)

PQ6 This car would seem to be durable (strongly disagree to strongly agree).

Service quality - seven-point scale: strongly disagree to strongly agree (0.95)

SQ1 The dealer's service department has up-to-date equipment.

SQ2 The physical facilities of the service department are visually appealing.

SQ3 When the dealer's service department promises to do something by a certain time, it does so.

SQ4 When you have problems, the service department is sympathetic and reassuring.

SQ5 The service department keeps its records accurately.

SQ6 You can trust these service employees.

SQ7 The service employees get adequate support from their dealer to do their jobs well.

SQ8 The service department at this dealer gives you individual attention.

SQ9 Employees of the service department know what your needs are.

SQ10The dealer's service department has operating hours convenient to all their customers.

Manufacturer ethical concern - six-point scale: completely false to completely true (0.94)

$\mathrm{MC} 1$ The major consideration of the company, which manufactures this car, is what is best for the customer.

MC2 Their most important concern is the good of the customer as a whole.

MC3 A major concern of the company, which produces the make of this car, is always what is best for the customer.

MC4 In this company, people look out for the customer's good.

MC5 In this manufacturing company, it is expected that employees will always do what is right for the customers and the public.

MC6 The most efficient way is always the right way in the company, which makes this car.

MC7 In this manufacturing company, each person, above all, seems to work efficiently.

General tendency to trust- seven-point scale: strongly disagree to strongly agree (0.77)

GT1 Generally speaking, you do not have to worry at all in dealing with other people.

GT2 Most people would not tell a lie even if they could gain by it.

GT3 Most people have standards regarding honesty and morality and will stick to them when the chips are down.

GT4 Most people are reliable because they are mainly concerned with the interests of others.

GT5 There are people in this world that you can completely trust.

Familiarity - seven-point scale (0.91)

F1 In general, would you consider yourself familiar or unfamiliar with the make of this car, before you first visited the dealership? (very familiar to very unfamiliar) (-)

F2 Would you consider yourself informed or uninformed about the make of this car, prior to first visiting the dealership? (highly informed to not at all informed) (-)

F3 Would you consider yourself knowledgeable or unknowledgeable about the make of this vehicle before you first visited the dealership? (knew a great deal to knew nothing at all) (-)

Satisfaction- seven-point scale (0.96)

S1 "Pleased" to "Displeased" (-)

S2 "Contented" to "Disgusted" (-)

S3 "Very Satisfied" to "Very Dissatisfied" (-)

S4 "Happy with the car" to "Unhappy with the car" (-)
S5 "This car does a good job for me" to "This car does a poor job for me" $(-)$

S6 "Wise choice in buying this car" to "Poor choice in buying this car" (-)

Trust of salesperson - seven-point scale: strongly disagree to strongly agree (0.97)

ST1 I believe what this salesperson says and that he/she would not try to take advantage of the customer.

ST2 He/she is straightforward and honest even though his/her interests are involved.

ST3 The salesperson is reliable because he/she is mainly concerned with the customer's interests, rather than his/her own.

ST4 Generally speaking, you do not have to worry at all in dealing with him/her.

ST5 Anyone could completely trust this salesperson.

ST6 The salesperson would not tell a lie even if he/she could gain by it.

ST7 $\mathrm{He} / \mathrm{she}$ has standards regarding honesty and morality and would stick to them when the chips are down.

ST8 This salesperson can be trusted; he/she really looks out for the customer.

Trust of manufacturer - seven-point scale: strongly disagree to strongly agree (0.94)

MT1The company, which manufactures this car can be trusted; it really looks out for the customer.

MT2This company is reliable because it is mainly concerned with the customer's interests.

MT3The company, which produces the make of this car would not tell a lie, even if it could gain by it.

MT4This manufacturing company has standards regarding honesty and morality and would stick to them when the chips are down.

Anticipation of future interaction - seven-point scale (0.96)

The next time I buy a car, I will choose the same make of car again.

A1 "Unlikely" to "Likely"

A2 "Not very probable" to "Probable"

A3 "Impossible" to "Very possible"

A4 "No chance" to "Certain"

Repurchase intention - seven-point scale

The next time I buy a car, I will choose the same make of car again.

R1 "Unlikely" to "Likely"

R2 "Not very probable" to "Probable"

\section{References}

Anderson JC, Narus JA. Toward a better understanding of distribution channel working relationships. In: Backhaus K, Wilson D, editors. Industrial Marketing: A German American American Perspective. Berlin: Springer-Verlag, 1986. pp. 320-36.

Anonymous. Complete salesmanship: that's what buyers appreciate. Purchasing (August) 1984;100:59-66.

Arndt J. Toward a concept of domesticated markets. J Mark (Fall) 1979;43:69-75.

Bagozzi RP. Evaluating structural equation models with unobservable variables and measurement error: a comment. J Mark Res (August) 1981; 18:375-81.

Bagozzi RP, Yi Y. On the evaluation of structural equation models. J Acad Mark Sci (Spring) 1988;16:74-94.

Berry LL. Relationship marketing of services - growing interest, emerging perspectives. J Acad Mark Sci 1995;23(4):236-45.

Bitner MJ. Building service relationships: it's all about promises. J Acad Mark Sci 1995;23(4):246-51. 
Bollen K. Structural Equations with Latent Variables. New York: Wiley, 1989.

Cronbach LJ. Coefficient alpha and internal structure of tests. Psychometrika (September) 1951;16:297-334.

Cronin JJ, Taylor S. Measuring service quality: a reexamination and extension. J Mark (July) 1992;56:55-68.

Crosby LA, Evans KR, Cowles D. Relationship quality in services selling: an interpersonal influence perspective. J Mark (July) 1990;54: $68-81$.

Deutsch M. Trust and suspicion. J Conflict Resolution (June) 1958;2: 265-79.

Doney PM, Cannon JP. An examination of the nature of trust in buyerseller relationships. J Mark (April) 1997;61:31-5.

Duncan OD. Introduction to Structural Equation Models. New York: Academic Press, 1975.

Dwyer FR, Lagace RR. On the nature and role of buyer-seller trust. In: T Shimp, Sharma S, editors. American Marketing Association Educators' Conference Proceedings. Chicago: American Marketing Association, 1986. pp. 40-5.

Dwyer FR, Oh S. A transaction cost perspective on vertical contractual structure and interchannel competitive strategies. J Mark (April) 1988;52:21-34.

Dwyer FR, Schurr PH, Oh S. Developing buyer-supplier relationships. J Mark (April) 1987;51:11-27.

Ferrell OC, Gresham L, Fraedrich J. A synthesis of ethical decision making models for marketing. J Macromark (Fall) 1989;9:55-64.

Ferrell OC, Weaver MK. Ethical beliefs of marketing managers. J Mark (July) 1978;42:69-73.

Fukuyama F. Trust: The Social Virtues and Creation of Prosperity. New York: The Free Press, 1995.

Ganesan S. Determinants of long-term orientation in buyer-seller relationships. J Mark (April) 1994;59:1 - 19.

Hallen L, Johanson J, Mohamed NS. Interfirm adaptation in business relationships. J Mark (April) 1991;55:29-37.

Hawes JM, Mast KE, Swan JE. Trust earning perceptions of sellers and buyers. J Personal Selling Sales Manage (Spring) 1989;9:1-8.

Heide JB, John G. The role of dependence balancing in safeguarding transaction-specific assets in conventional channels. J Mark (January) 1988;52:20-35.

Heide JB, John G. Alliances in industrial purchasing: the determinants of joint action in buyer-supplier relationships. J Mark Res (February) 1990;27:24-36.

Heide JB, John G. Do norms matter in marketing relationships? J Mark (April) 1992;56:32-44.

Herndon N. Commitment, satisfaction and turnover: the impact of individual moral value structures when exposed to a conflicting or matching organizational sales culture. A Dissertation. Texas A\&M University, 1991.

Holden RK. An exploratory study of trust in buyer-seller relationships. A Dissertation, University Microfilms International, Ann Arbor, MI, 1990.

Hosmer LRT. Trust: the connecting link between organizational theory and philosophical ethics. Acad Manage Rev (April) 1995;20:379-403.

Hosmer LRT. 5 years and 141 articles of BEQ. Bus Ethics Q (July) 1996;6:325-58.

Kellerman K. Information exchange in social interaction. In: Roloff ME, Miller R, editors. Interpersonal Processes: New Directions in Communication Research (Vol. 14). London: Sage Publications, 1987. pp. $140-56$.

Kelley S, Dorsch MJ. Ethical climate, organizational commitment, and indebtedness among purchasing executives. J Personal Selling Sales Manage (Fall) 1991;11:55-65.

Kelley S, Skinner SJ, Ferrell OC. Opportunistic behavior in marketing research organizations. J Bus Res (June) 1989;18:327-40.

Kim J-O, Mueller CW. Introduction to factor analysis. Sage University Paper Series on Quantative Applications in the Social Sciences Beverly Hills, CA: Sage Publications, 1978 no. 07-013.
Kurland NB. Accountability, and sales agents' dueling loyalties. Bus Ethics Q (July) 1996;6:289-310.

Lagace R, Dahlstrom R, Gassenheimer JB. The relevance of ethical salesperson behavior on relationship quality: the pharmaceutical industry. J Personal Selling Sales Manage (Fall) 1991;11:39-47.

Loe T. The role of ethical climate in developing trust, market orientation, and commitment to quality. A Dissertation. University of Memphis, 1996.

Matthews BA, Shimoff E. Expansion of exchange monitoring trust levels in ongoing exchange relations. J Conflict Resolution 1979;23: $538-60$.

Moorman C, Deshpande R, Zaltman G. Factors affecting trust in market research relationships. J Mark (January) 1993;57:81-101.

Morgan RM, Hunt SD. The commitment-trust theory of relationship marketing. J Mark (July) 1994;58:20-38.

Nunnally JC. Psychometric Theory (2nd edn.). New York: McGrawHill, 1978.

Oliver RL, Bearden W. Crossover effects in the theory of reasoned action: a moderating influence attempt. J Consum Res (December) $1985 ; 12: 324-40$

Oliver RL, Swan JE. Consumer perceptions of interpersonal equity and satisfaction in transactions: a field survey approach. J Mark (April) 1989;53:21-35.

Oliver RL, Swan JE. Equity and disconfirmation perceptions as influences on merchant and product satisfaction. J Consum Res (December) 1989; $16: 372-83$

Parasuraman A, Berry L, Zeithaml V. SERVQUAL: a multiple-item scale for measuring consumer perceptions of service quality. J Retailing 1991;64:12-37.

Parasuraman A, Zeithaml V, Berry L. A conceptual model of service quality and its implications for future research. J Mark (Fall) 1985;49: $41-50$.

Pedhazur EJ. Multiple Regression in Behavioral Research (2nd edn.). New York: Holt, Rinehart and Winston, 1982.

Petroshius SM, Monroe KB. Effect of product-line pricing characteristics on product evaluations. J Consum Res (March) 1987;13:511-9.

Pruitt DG. Definition of the situation as a determinant of international action. In: Kelman HS, editor. International Behavior: A Social Psychological Analysis. New York: Holt, Rinehart and Winston, 1965. pp. $36-52$.

Rotter JB. A new scale for the measurement of interpersonal trust. J Personality 1967;35(4):651-65.

Scanzoni J. Social exchange and behavioral interdependence. In: Burgess TL, Huston TL, editors. Social Exchange in Developing Relationships. New York: Academic Press, 1979. pp. 103-27.

Scheer L, Stern LW. The effect of influence type and performance outcomes on attitude toward the influencer. J Mark Res (February) 1992;29:128-42.

Sheth JN, Parvatiyar A. Relationship marketing in consumer markets: antecedents and consequences. J Acad Mark Sci. 1996;23(4):255-71.

Swan JE, Nolan JJ. Gaining customer trust: a conceptual guide for the salesperson. J Personal Selling Sales Manage (November) 1985;5:39-48.

Swan JE, Trawick FI, Rink DR, Roberts JJ. Measuring dimensions of purchaser trust of industrial salespeople. J Personal Selling Sales Manage 1988;8(1):1-9.

Swan JE, Trawick FI, Silva D. How industrial salespeople gain customer trust. Ind Mark Manage 1985;14:203-11.

Victor B, Cullen JB. A theory and measure of ethical climate in organizations. In: Frederick W, Preston LE, editors. Research in Corporate Social Performance and Policy. Greenwich, CT: JAI Press, 1987. pp. $51-71$.

Victor B, Cullen JB. The organizational bases of ethical work climates. Administrative Sci Q (March) 1988;33:101-25.

Weitz B. Effectiveness in sales interactions: a contingency framework. J Mark (Winter) 1981;45:85-103.

Westbrook RA, Oliver RL. Developing better measures of consumer satisfaction: some preliminary results. In: Monroe KB, editor. Advances in 
Consumer Research (Vol. 8). Ann Arbor, MI: Association for Consumer Research, 1981. pp. 94-9.

Worchel P. Trust and distrust. In: Austin WB, Worchel S, editors. Social Psychology and Intergroup Relations. Belmont, CA: Wadsworth, 1979. pp. $243-59$.
Zand D.E.. Trust and managerial problem solving. Administrative Sci Q 1972;17:229-39.

Zucker LG. Production of trust: institutional sources of economic structure, 1840-1920. In: Staw BM, Cummings LL, editors. Research in Organizational Behavior (Vol. 8). New York: JAI Press, 1986. pp. 53-111. 